\title{
KESEMPATAN KERJA DAN PENDAPATAN PELAKU PEMASARAN AGRIBISNIS ONLINE DI KOTA MATARAM
}

\section{EMPLOYMENT OPPORTUNITIES AND INCOME FOR ONLINE AGRIBUSINESS MARKETING PLAYERS IN THE CITY OF MATARAM}

Silvia Dinan Sari, Anas Zaini dan Ibrahim

Program Studi Agribisnis Fakultas Pertanian Universitas Mataram

\begin{abstract}
ABSTRAK
Penelitian ini bertujuan untuk : (1) menganalisis kesempatan kerja dari pelaku pemasaran agribisnis online (driver Go-Food dan driver Grab Food) di Kota Mataram; dan (2) menganalisis pendapatan dari pelaku pemasaran agribisnis online (driver Go-Food dan driver Grab Food) di Kota Mataram. Metode yang digunakan adalah metode deskriptif. Data di analisis dengan menggunakan perhitungan HKO (Hari Kerja Orang) dan dengan menggunakan analisis biaya dan pendapatan.

Penelitian ini dilakukan di Kota Mataram, karena saat ini di Kota Mataram sedang gencar-gencarnya penggunaan fitur layanan Go-Food dan Grab Food. Pengambilan responden dalam penelitian ini dengan cara accidental sampling. Sedangkan penentuan jumlah responden dalam penelitian ini ditetapkan sebanyak 40 responden dengan menggunakan quota samplin. Jenis data dalam penelitian ini adalah data kualitatif dan kuantitatif, sedangkan sumber data dalam penelitian ini adalah data primer dan sekunder.

Hasil penelitian menunjukkan bahwa; (1) Kesempatan kerja/peluang kerja dari pelaku pemasaran agribisnis online di Kota Mataram berdasarkan perhitungan sebesar 5.920 HKO dengan hasil perhitungan HKO untuk per individu sebesar 1,6 HKO/orang dengan rata-rata jam kerja sehari selama 11.45 jam/hari; dan (2) Rata-rata pendapatan yang diterima oleh pelaku pemasaran agribisnis online di Kota Mataram per bulan sebesar Rp 2.131.449
\end{abstract}

Kata Kunci: Kesempatan kerja, Go-Food, Grab Food 


\begin{abstract}
The objectives of this research are: (1) analyze the employment opportunities of online agribusiness marketing players (driver Go-Food and driver Grab Food) in the city of Mataram; and (2) analyze the income of online agribusiness marketing practitioners (driver Go-Food and driver Grab Food) in the city of Mataram. The method used is decriptive method. Data were analyzed using HKO (working days for people) and using cost and income.

This research was conducted in the city of Mataram, because at this time in the city of Mataram was incessant use of the features of Go-Food and Grab Food services. Respondents in this study was taking by accidental sampling. While the determination of the number of respondents in this research was set as many as 40 respondents using quota sampling. The type of data in this research is qualitative and quantitative data, while the souece of data in this research is primary and secondary.

The results showed that; (1) employment opportunities/job opportunities from online agribusiness marketing players (driver Go-Food and driver Grab Food) in the city of Mataram based on a calculation is $5.920 \mathrm{HKO}$ with the results of the HKO calculation for the first individual is 1,6 HKO/person with an average working hours a day for 11.45 hours/day; and (2) the average income received by online agribusiness marketing players in the city of Mataram a month is Rp 2.131.449.
\end{abstract}

Key words: Emplyment opportunities, Go-Food, Grab Food

\title{
PENDAHULUAN
}

Dalam bidang agribisnis didapat berbagai istilah yang dapat digunakan secara bersamaan (interchangeable), misalnya pemasaran produk pertanian (agriculture product marketing) dan pemasaran produk makanan (food marketing), dimana untuk tujuan terbatas istilah tersebut dapat digunakan secara umum. Agribisnis dapat didefinisikan sebagai keseluruhan kegiatan meliputi manufaktur, distribusi kebutuhan usahatani, proses produksi usahatani, penyimpanan, pengolahan, serta distribusi hasil atau komoditas dari usahatani dan jenis lainnya. Adapun salah satu produk yang diamati dalam bidang agribisnis, yaitu produk makanan termasuk serat (food and fiber).

Indonesia merupakan suatu negara yang memiliki serta menyajikan berbagai produk kuliner. Makanan Indonesia merupakan pencerminan beragam budaya dan tradisi yang berasal dari kepulauan Nusantara. Sebagian dari kuliner Indonesia sudah banyak yang dikenal dan masih banyak juga yang belum terkuak, karena beragamnya produk tersebut tidak semua masyarakat mengetahui dan mengenal makanan-makanan serta produk kuliner yang ada secara menyeluruh.

Pada era modern saat ini, manusia memiliki kehidupan dengan segala aktivitas yang tidak akan pernah lepas dari perkembangan teknologi. Teknologi sangat berperan penting dalam perkembangan zaman karena dapat membuka cakrawala baru dalam perkembangan pembangunan bangsa. Berkembangannya teknologi yang 
semakin cepat dapat dilihat bahwa sekarang ini dalam bidang transportasi sedang digencarkan dengan munculnya transportasi darat berbasis aplikasi android online. Transportasi berbasis aplikasi online ini merupakan penggabungan dari segi jasa transportasi ojek dan teknologi komunikasi. Salah satu hasil produk jasa transportasi yang sedang populer saat ini adalah aplikasi Go-Jek dan Grab. Dimana aplikasi GoJek dan Grab merupakan beberapa diantara layanan ojek online yang banyak menawarkan layanan jasa, seperti berupa : antar-jemput, pesan antar makanan, belanja barang, antar barang dan jenis layanan lainnya. Salah satu layanan jasa yang paling popoler sekarang ini adalah layanan jasa pesan antar makanan (food delivery). Yang dimana pada aplikasi Go-Jek dikenal dengan fitur layanan Go-Food dan pada aplikasi Grab dikenal dengan fitur layanan yang disebut dengan Grab Food. Baik Go-Food maupun Grab Food merupakan layanan yang melayani food delivery service di Indonesia.

Begitu juga di daerah Kota Mataram, Provinsi Nusa Tenggara Barat. Aplikasi ojek online (Go-Jek dan Grab) saat ini sedang lagi ramai-ramainya diperbincangkan, karena ojek online dapat mempermudah aktivitas masayarakat baik untuk kalangan muda ataupun untuk orangtua. Ojek online (Go-Jek dan Grab) merupakan transportasi terobosan terbaru yang menggunakan aplikasi berbasis online, dimana dengan adanya terobosan terbaru ini dapat menciptakan kesempatan kerja atau lapangan kerja bagi masyarakat yang menganggur.

Kota Mataram merupakan salah satu dari 10 (sepuluh) kabupaten/kota di Provinsi Nusa Tenggara Barat dengan pertumbuhan penduduk yang terus meningkat dari tahun ke tahun yang tidak diimbangi dengan pertumbuhan lapangan pekerjaan sehingga menimbulkan adanya pengangguran. Berdasarkan Badan Pusat Statistik (BPS), pada tahun 2016 jumlah penduduk secara keseluruhan adalah 459.314 jiwa, dan pada tahun 2017 jumlah penduduk Kota Mataram secara keseluruhan adalah 468.509 jiwa. Berdasarkan data tersebut dapat dilihat bahwa dari tahun 2016-2017 mengalami peningkatan jumlah penduduk sebesar $2,00 \%$.

Selain itu, Badan Pusat Statistik (BPS) Provinsi Nusa Tenggara Barat mencatat jumlah penduduk pengangguran di Nusa Tenggara Barat (NTB) pada Agustus 2018 mencapai 83.527 orang yang tersebar di 9 kabupaten/kota tidak termasuk kabupaten Lombok Utara. Jumlah pengangguran tertinggi berada di Kota Mataram mencapai 14.934 orang atau $6,72 \%$. Dimana hal ini disebabkan karena bencana alam (Gempa Bumi) yang melanda wilayah Nusa Tenggara Barat secara umum, mengakibatkan lemahnya perekonomian masyarakat sehingga berdampak pada peningkatan angka pengangguran. Berdasarkan uraian di atas maka dilakukan penelitian yang berjudul "Kempatan Kerja dan Pendapatan Pelaku Pemasaran Agribisnis Online di Kota Mataram".

Penelitian ini bertujuan untuk: (1) menganalisis kesempatan kerja dari pelaku pemasaran agribisnis online (driver Go-Food dan driver Grab Food) di Kota Mataram; dan (2) menganalisis pendapatan dari pelaku pemasaran agribisnis online (driver Go-Food dan driver Grab Food) di Kota Mataram. Hasil penelitian diharapkan dapat menjadi bahan pertimbangan dari berbagai pihak khususnya masayarakat yang ingin bekerja atau bergabung menjadi driver baik di perusahaan Go-Jek maupun di Grab. 


\section{METODE PENELITIAN}

Penelitian ini menggunakan metode penelitian deskriptif yang bersifat menggali permasalahan yang ditujukan pada penemuan fakta berdasarkan gejala faktual tentang perilaku kelompok masyarakat dan pengumpulan data dengan teknik wawancara. Unit analisis dalam penelitian ini adalah pelaku pemasaran agribisnis online (driver Go-Food dan Grab Food) di Kota Mataram.

Penelitian ini dilakukan di Kota Mataram, dimana Kota Mataram merupakan salah satu kota yang telah menggunakan jasa ojek online. Penentuan jumlah responden dalam penelitian ini ditetapkan sebanyak 40 responden dengan menggunakan quota samplin. Sedangkan pengambilan responden dalam penelitian ini dengan cara accidental sampling (teknik penentuan sampel secara kebetulan atau tidak sengaja). Variabel penelitian dan cara pengukurannya adalah sebagai berikut:

- Penghasilan per hari yang diterima driver Go-Food dan Grab Food dinyatakan dengan satuan Rrpiah (Rp).

- Bonus transakasi per hari adalah pengahasilan yang diterima oleh driver Go-Food dan Grab Food dengan mengkalikan jumlah poin atau jumlah orderan yang diterima dengan uang yang telah ditetapkan oleh perusahaan yang dinyatakan dengan satuan rupiah (Rp).

- Rata-rata pengurangan pendapatan merupakan pembagian hasil untuk pihak perusahaan dari setiap pembayaran oleh konsumen yang diterima oleh driver yang dinyatakan dengan satuan rupiah $(\mathrm{Rp})$.

- Biaya bensin adalah salah satu biaya yang harus dikeluarkan oleh driver yang berpengaruh untuk melakukan transaksi yang dinyatakan dengan satuan rupiah (Rp).

- Biaya makan adalah biaya yang termasuk unsur-unsur perhitungan pendapatan dikarenakan driver tidak setiap waktu dapat makan di rumah yang dinyatakan dengan satuan rupiah (Rp).

- Biaya pulsa per bulan merupakan termasuk unsur-unsur dalam perhitungan pendapatan, dimana masing-masing driver untuk biaya pulsa per bulan pasti berbeda-beda yang dinyatakan dengan satuan rupiah (Rp).

- Biaya penyusutan alat merupakan biaya yang termasuk unsur-unsur dalam perhitungan pendapatan, dimana biaya penyusutan alat seperti biaya penyusutan sepeda motor dan biaya penyusutan handphone yang dinyatakan dengan satuan rupiah $(\mathrm{Rp})$.

- Biaya lain-lain merupakan biaya yang termasuk unsur-unsur dalam perhitungan pendapatan, dimana biaya lain-lain seperti biaya service motor dan biaya tak terduga seperti biaya apabila dalam beroperasi driver mengalami pecah atau bocor ban motor yang dinyatakan dengan satuan rupiah (Rp).

Pendapatan yang dimaksud dalam penelitian ini adalah pendapatan yang diperoleh driver Go-Food maupun Grab Food, dengan rumus sebagai berikut : 


\section{Pendapatan $(\mathbf{P d})=$ TR + Bonus - TC}

Dimana:
Pendapatan $(\mathrm{Pd})=$ Penghasilan yang diterima oleh pelaku pemasaran agribisnis online (driver Go-Food dan Grab Food).
TR $=$ Penghasilan per bulan.
Bonus $\quad=$ Jumlah poin yang dinominalkan dengan uang.
TC = Total biaya yang dikeluarkan mulai dari deposit, pengurangan rata-rata, biaya bensin, biaya makan, dan biaya pulsa).

Kesempatan kerja dalam penelitian ini adalah jumlah kesempatan kerja/ peluang kerja dari pelaku pemasaran agribisnis online di Kota Mataram.

Untuk menganalisis kesempatan kerja dapat menggunakan perhitungan HKO (Hari Kerja Orang) dan dikaitkan dengan jumlah driver ojek online di Kota Mataram, sehingga secara matematis dapat dihitung dengan:

$$
\text { HKO }=\frac{\mathbf{t} \times \mathbf{h} \times \mathbf{j}}{7}
$$

Dimana:

$\mathrm{t}=$ Jumlah tenaga kerja

$\mathrm{h}=$ Jumlah hari kerja

$\mathrm{j}=$ Jumlah jam kerja

7 = Standar jam kerja per hari

\footnotetext{
Kesempatan kerja $=$ Jumlah pelaku pemasaran (driver) $x$ Rata-rata $\mathrm{HKO}$

Kesempatan kerja = Kesempatan kerja/peluang kerja dari pelaku pemasaran agribisnis online (driver Go-Food dan Grab Food).

Jumlah pelaku pemasaran (driver) = Jumlah dari driver Go-jek dan Grab.

Rata-rata HKO

$=$ Nilai rata-rata $\mathrm{HKO} /$ orang.
} 


\section{HASIL DAN PEMBAHASAN}

\section{Karakteristik Responden}

Karakteristik responden pelaku pemasaran agribisnis online (driver Go-Food dan driver Grab food) di Kota Mataram disajikan pada Tabel 1.

Tabel 1. Karakteristik Responden pelaku pemasaran agribisnis online (driver Go-Food dan driver Grab food) di Kota Mataram Tahun 2020

\begin{tabular}{rrr}
\hline No & \multicolumn{1}{c}{ Uraian } & Responden \\
\hline 1 Jumlah Sampel (n) & 40 \\
2 Umur (Tahun) & 28 \\
& Rata-rata & $17-56$ \\
& Kisaran & \\
3 Tingkat Pendidikan & $2(5,0 \%)$ \\
SD & $4(10,0 \%)$ \\
SMP & $25(62,5 \%)$ \\
SMA/SMK & $9(22,5 \%)$ \\
Perguruan Tinggi & 2 \\
4 Jumlah Tanggungan Keluarga & $1-6$ \\
Rata-rata & \\
Kisaran & 1,6 \\
Pengalaman/ Laman Bergabung & $1-3$ \\
Rata-rata & \\
Kisaran &
\end{tabular}

Sumber: Data primer yang diolah (2020).

Umur Responden. Hasil penelitian menunjukkan bahwa rata-rata umur pelaku pemasaran agribisnis online (driver G0-food dan driver Grab food) di Kota Mataram adalah berumur 28 tahun dengan kisaran umur 17-56 tahun. Artinya bahwa rata-rata responden termasuk kedalam kelompok usia produktif dengan kemampuan aktivitas yang cukup tinggi untuk melakukan kegiatan sehari-hari dalam melakukan pemasaran agribisnis online serta kemampuan dalam penyerapan informasi dan teknologi inovasi terbaru.

Tingkat Pendidikan. Berdasarkan Tabel 1 dapat diketahui bahwa sebagian besar responden pelaku pemasaran agribisnis online (driver G0-food dan driver Grab food) di Kota Mataram adalah tamatan SMA/SMK sebanyak 25 orang (62,5\%), dan sisanya memilki tingkat pendidikan pada tingkat SD sebanyak 2 orang $(5,0 \%)$, tingkat SMP sebanyak 4 orang (10,0\%), dan pada tingkat Perguruan Tinggi sebanyak 9 orang $(22,5 \%)$.

Jumlah Tanggungan Keluarga. Berdasarkan Tabel 1 menunjukkan bahwa rata-rata jumlah tanggungan keluarga pelaku pemasaran agribisnis online (driver G0food dan driver Grab food) sebanyak 2 orang dengan kisaran 1-6 orang. 
Pengalaman/Lama Bergabung. Berdasarkan Tabel 1 dapat diketahui bahwa rata-rata pengalaman/lama bergabung pelaku pemasaran agribisnis online (driver GoFood dan driver Grab Food) adalah 1,6 tahun dengan kisaran lama bergabung antara 1-3 tahun. Hasil penelitian ini menunjukkan bahwa responden masih tergolong cukup baru, sehingga kadang masih banyak masalah yang dihadapi dalam menerima orderan, namun seiring berjalannya waktu para pelaku pemasaran ini dapat mengatasi permasalahan yang dihadapi.

\section{Analisis Kesempatan Kerja dari Pelaku Pemasaran Agribisnis Online di Kota Mataram}

Kesempatan kerja mengandung pengertian lapangan pekerjaan dan kesempatan untuk bekerja yang ada dari suatu kegiatan ekonomi (produktif). Kesempatan yang dimaksud dalam penelitian ini adalah kesempatan kerja/peluang kerja dari pelaku pemasaran agribisnis online (driver Go-Food dan Grab Food). Yang mana hal ini tercipta karena perkembagan teknologi yang terus berkembang.

Sehingga kehadiran tranportasi berbasis online di Kota Mataram menjadi angin segar bagi banyak kalangan masyarakat yang hanya memiliki jenjang pendidikan terakhir yang dapat dikategorikan menengah/tertentu. Pasalnya baik perusahaan Go-Jek maupun Grab memberikan peluang bekerja bagi masyarakat di Kota Mataram tanpa ada mensyaratkan status jenjang pendidikan yang dimiliki.

Oleh karena itu, kehadiran transportasi berbasis online di tengah-tengah masyarakat di Kota Mataram memberikan kesempatan kerja bagi masyarakat yang ingin bergabung menjadi mitra kerja, tanpa mengkhawatirkan status ijazah pendidikan yang dimiliki. Cukup hanya dengan menunjukkan segala kebutuhan administrasi berkendara roda dua dan memiliki handphone android, maka seseorang tersebut dapat bergabung menjadi mitra Go-Jek ataupun Grab. Hal ini selaras dengan hasil data di lapangan, yang dimana berdasarkan Tabel 2 diketahui bahwa penyerapan tenaga kerja oleh perusahaan baik perusahaan Go-Jek maupun Grab lebih didominasi oleh masyarakat yang memilki jenjang pendidikan terakhir pada tingkat SMA/SMK.

Hal ini juga dapat dilihat bahwa peranan Go-Food dan Grab Food di Kota Mataram dapat mengurangi tingkat pengangguran di Kota Mataram. berdasarkan data di lapangan diketahui bahwa pekerjaan sebagai pelaku pemasaran agribisnis online (driver Go-Food dan Grab Food) dapat dijadikan sebagai pekerjaan utama dan sebagai pekerjaan sampingan. Adapun rinciaan driver berdasarkan tipe pekerjaannya dapat dilihat pada Tabel 2.

Tabel 2. Riciaan Tipe Pekerjaan Pelaku Pemasaran Agribisnis Online (Driver) di Kota Mataram Tahun 2020

\begin{tabular}{llcc}
\hline \multirow{2}{*}{ No } & Jenis pekerjaan & \multicolumn{2}{c}{ Pelaku pemasaran agribisnis online } \\
\cline { 3 - 4 } & & Jumlah (orang) & Persentase (\%) \\
\hline 1 & Karyawan/pegawai & 9 & 22,5 \\
2 & Wiraswasta & 6 & 15,0 \\
3 & Pelajar/mahasiswa & 4 & 10,0 \\
4 & Pekerja lepas & 1 & 2,5 \\
5 & Driver (pengemudi) & 20 & 50,0 \\
\hline & Jumlah & 40 & 100 \\
\hline
\end{tabular}

Sumber: Data Primer yang diolah (2020) 
Berdasarkan Tabel 2 diketahui bahwa banyak masyarakat menjadikan pekerjaan sebagai pelaku pemasaran agribisnis online (driver Go-Food dan Grab Food) sebagai pekerjaan utama. Pada Tabel 2 dapat dilihat bahwa terdapat 20 orang (50\%) menjadikan pekerjaan sebagai pelaku pemasaran agribisnis online (driver GoFood dan Grab Food) sebagai pekerjaan utama. Dan ada juga yang menjadikan sebagai pekerjaan sampingan. Adapun faktor-faktor yang dapat menarik masyarakat baik yang sudah memiliki pekerjaan maupun yang belum bekerja untuk bergabung menjadi driver yaitu:

1. Cara kerja yang fleksibel artinya terbuka bagi siapa saja dan tidak memandang usia dan gender. Kebebasan dalam menentukan waktu kerja seperti ini banyak dicari masyarakat yang ingin mendapat tambahan penghasilan dengan kata lain dapat dimungkinkan memberi peluang sebagai pekerjaan sampingan.

2. Cara kerja yang memberi kemudahan dalam pelayanannya karena berbasis IT. Cara kerja yang mudah dan efisien karena menggunakan aplikasi berbasis teknologi yang dapat diakses kapan saja dan oleh siapa saja.

3. Memberikan kemudahan dalam pengalokasian waktu karena bisa dikerjakan kapan saja sesuai dengan kemampuan mitra kerja (driver).

Selain itu syarat yang ditentukan oleh perusahaan baik perusahaan Go-Jek maupun Grab tidak terlalu membebankan masyarakat. Syarat yang harus dipenuhi untuk dapat bergabung menjadi driver yaitu minimal memiliki kendaraan pribadi lengkap dengan STNK yang aktif, SKCK, Surat Keterangan Rumah Sakit, berumur minimal 17 tahun dan sudah memiliki KTP dan maksimal berumur 55 tahun, memiliki surat izin mengemudi (SIM C), dan memiliki smartphone.

Hasil analisis perhitungan HKO (Hari Kerja Orang) untuk Pelaku Pemasaran Agribisnis Online, jenis kegiatan pesan antar makanan (food delivery) di Kota Mataram Tahun 2020, rata-rata dalam sehari bekerja sebesar 1,6 HKO/orang, dengan rata-rata jam kerja sebesar 11,45 jam/hari. Artinya dapat dikatakan bahwa pada kegiatan pemasaran agribisnis online khususnya kegiatan pesan antar makanan/food delivery rata-rata sebesar 1,6 HKO/orang. Dengan demikian kesempatan kerja dari pemasaran agribisnis online (driver Go-Food dan driver Grab Food yang berjumlah 3.700 orang) di Kota Mataram adalah:

$$
\begin{aligned}
\text { Kesempatan kerja } & =\text { Jumlah pelaku pemasaran (driver) } \times \text { Rata-rata } \mathrm{HKO} \\
& =3.700 \times 1,6 \mathrm{HKO}=5.920 \mathrm{HKO}
\end{aligned}
$$

Artinya berdasarkan analisis yang telah dilakukan dapat diketahui bahwa kesempatan kerja/peluang kerja dari pelaku pemasaran agribisnis online (driver GoJek dan driver Grab) di Kota Mataram sebesar 5.920 HKO.

\section{Analisis Pelaku Pemasaran Agribisnis Online}

Sekarang ini peranan dari pelaku pemasaran agribisnis online tidak dapat dikesampingkan, karena pelaku pemasaran agribisnis online memiliki peranan yang penting, dimana dapat dilihat dari pemasaran produk-produk pertanian itu sendiri, tanpa adanya pelaku pemasaran maka produk-produk baik barang maupun jasa tidak dapat dapat sampai ke tangan konsumen akhir.

Seperti diketahui, sejak diluncurkan pada tahun 2015, keberadaan aplikasi GoFood telah merambah ke 204 kota dan kabupaten di Indonesia hingga saat ini. tak hanya itu Go-Food juga berekspansi di kawasan Asia Tenggara. Adapun Grab Food 
yang baru hadir telah merambah 178 kota di Indonesia dan di beberapa negara lain di kawasan Asia Tenggara. Seperti yang dirasakan saat ini, Kota Mataram merupakan salah satu kota yang termasuk ke 204 kota dan kabupaten yang menggunakan jasa Go-Food maupun Grab Food.

Analisis penerimaan, biaya dan pendapatan pelaku pemasaran agribisnis online di Kota Mataram diuraikan berikut ini.

\section{Analisis Penerimaan Pelaku Pemasaran Agribisnis Online}

Penerimaan dalam penelitian ini adalah sejumlah uang yang diterima oleh pelaku pemasaran agribisnis online (driver Go-Food dan Grab Food) atas jumlah orderan yang diterima dan bonus transaksi yang diterima. Bonus yang diterima berbeda dengan penerimaan yang diterima berdasarkan ongkos kirim (ongkir) yang diterima.

Tabel 3. Rata-rata Penerimaan Per hari dan per Bulan Pelaku Pemasaran Agribisnis Online di Kota Mataram Tahun 2020

\begin{tabular}{clrl}
\hline No & Jenis Penerimaan & Per Hari & Per Bulan \\
\hline 1 & Penghasilan (Rp) & 111.775 & 3.032 .300 \\
2 & Bonus Transaksi (Rp) & 51.125 & 1.385 .375 \\
\hline & Jumlah & 162.900 & 4.417 .675 \\
\hline
\end{tabular}

Sumber: Data Primer yang diolah (2020)

Tabel 3 menunjukkan bahwa rata-rata penerimaan pelaku pemasaran agribisnis online (driver Go-Food dan Grab Food) per hari sebesar Rp 162.900 atau per bulan Rp 4.417.675. Penerimaan ini dihasilkan berdasarkan jumlah orderan yang diterima dikalikan dengan biaya onkos kirim (ongkir) ditambah dengan bonus yang diterima.

\section{Analisis Biaya yang Dikeluarkan Pelaku Pemasaran Agribisnis Online}

Biaya yang dimaksud dalam penelitian ini adalah segala bentuk biaya yang dikeluarkan secara langsung maupun tidak langsung dalam melakukan pemasaran produk agribisnis berbasis online. Biaya dibagi menjadi dua yaitu biaya variabel dan biaya tetap. Biaya variabel adalah biaya yang besar kecilnya bergantung pada jumlah orderan yang diterima sedangkan biaya tetap adalah biaya yang besar kecilnya tidak bergantung pada jumlah orderan yang diterima. Rata-rata biaya yang dikeluarkan oleh pelaku pemasaran agribisnis online disajikan pada Tabel 4.

Tabel 4 menunjukkan bahwa jenis biaya variabel yang dikeluarkan oleh pelaku pemasaran agribisnis online yaitu potongan penghasilan, biaya makan, biaya bensin, biaya pulsa dan biaya lain-lain. Rata-rata biaya variabel yang dikeluarkan oleh pelaku pemasaran agribisnis online dengan rata-rata hari kerja selama 27 hari dalam satu bulan sebesar $\mathrm{Rp} 2.057 .035$ dan rata-rata biaya tetap seperti penyusutan alat (penyusutan sepeda motor dan penyusutan handphone) sebesar Rp 229.191. Dengan demikian total biaya yang dikeluarkan per bulan oleh pelaku pemasaran agribisnis online di Kota Mataram sebesar Rp 2.286.226. 
Tabel 4. Rata-rata Biaya yang Dikeluarkan per Bulan oleh Pelaku Pemasaran Agribisnis Online di Kota Mataram 2020

\begin{tabular}{|c|c|c|}
\hline No & $\begin{array}{r}\text { Jenis Biaya } \\
\end{array}$ & Per Bulan \\
\hline \multicolumn{3}{|c|}{ 1. $\quad$ Biaya Variabel $(\mathrm{Rp})$} \\
\hline & a. Potongan penghasilan ( $\mathrm{Rp})$ & 409.110 \\
\hline & b. Biaya makan (Rp) & 946.125 \\
\hline & c. Biaya bensin (Rp) & 503.125 \\
\hline & d. Biaya pulsa (Rp) & 73.250 \\
\hline & e. Biaya lain-lain (Rp) & 125.425 \\
\hline & Sub total biaya variabel & 2.057 .035 \\
\hline \multicolumn{3}{|c|}{ Biaya Tetap (Rp) } \\
\hline & Penyusutan alat (Rp) & 229.191 \\
\hline & Sub total biaya tetap & 229.191 \\
\hline & Total & 2.286 .226 \\
\hline
\end{tabular}

Sumber: Data Primer yang diolah (2020)

\section{Analisis Pendapatan Pelaku Pemasaran Agribisnis Online}

Pendapatan pelaku pemasaran agribisnis online adalah selisih antara total penerimaan yang diterima pelaku pemasaran agribisnis online (driver Go-Food dan Grab Food) total biaya yang dikeluarkan oleh pelaku pemasaran agribisnis online (driver Go-Food dan Grab Food). Rata-rata pendapatan pelaku pemasaran agribisnis online di Kota Mataram disajikan pada Tabel 5.

Tabel 5. Rata-rata Pendapatan Per Bulan Pelaku Pemasaran Agribisnis Online di Kota Mataram Tahun 2020

\begin{tabular}{clc}
\hline No & \multicolumn{1}{c}{ Uraian } & Per Bulan \\
\hline 1. & Penghasilan $(\mathrm{Rp})$ & 3.032 .300 \\
2. & Bonus transaksi (Rp) & 1.385 .375 \\
3. & Total biaya (Rp) & 2.286 .226 \\
\hline 4. & Pendapatan $(\mathrm{Rp})$ & 2.131 .449 \\
\hline
\end{tabular}

Sumber: Data primer diolah (2020)

Berdasarkan Tabel 5 dapat diketahui bahwa rata-rata pendapatan per bulan pelaku pemasaran agribisnis online di Kota Mataram sebesar Rp 2.131.449. Besar kecilnya pendapatan yang diterima oleh pelaku pemasaran agribisnis online sangat dipengaruhi oleh besar kecilnya penerimaan yang diterima dan biaya-biaya yang dikeluarkan. Semakin besar orderan dan bonus transaksi yang diterima akan dapat meningkatkan pendapatan pelaku pemasaran agribisnis online. Pendapatan per bulan yang diterima oleh pelaku pemasaran agribisnis online (driver Go-Food dan Grab Food) di Kota Mataram hampir sama dengan besarnya UMK Kota Mataram tahun 2020 sebesar Rp 2.184.485. 


\section{KESIMPULAN DAN SARAN}

\section{Kesimpulan}

1. Kesempatan kerja/peluang kerja dari pelaku pemasaran agribisnis online di Kota Mataram berdasarkan perhitungan sebesar 5.920 HKO dengan hasil perhitungan $\mathrm{HKO}$ untuk per individu sebesar 1,6 HKO/orang dengan rata-rata jam kerja sehari selama $11,45 \mathrm{jam} / \mathrm{hari}$.

2. Rata-rata pendapatan yang diterima oleh pelaku pemasaran agribisnis online di Kota Mataram per bulan sebesar Rp 2.131.449.

\section{Saran}

Diharapkan untuk penelitian selanjutnya yaitu penyebaran kuisioner secara merata berdasarkan seluruh kecamatan yang ada di Kota Mataram, agar memperoleh hasil yang maksimal yaitu dapat mewakili seluruh kecamatan yang ada di Kota Mataram.

\section{DAFTAR PUSTAKA}

Badan Pusat Statistik. 2019. Kota Mataram Dalam Angka 2019. BPS Kota Mataram.

Marsusanti, Eva, Susilawati dan Rusli Nugraha. 2018. Faktor-Faktor Yang Mempengaruhi Pendapatan Driver Gojek. Jurnal Swabumi 6: 128-129.

Mursid, M. 2010. Manajemen Pemasaran. Edisi 1. Bumi Aksara. Jakarta.

Ompusunggu, Vina Maria. 2018. Analisis Penyerapan Tenaga Kerja Pada Transportasi Online di Kota Medan. Jurnal Ilmu Ekonomi Dan Studi Pembangunan 18: 15-17.

Rakhmatulloh, Anita Ratnasari, et al. 2018. Dampak Transportasi Berbasis Aplikasi Terhadap Penyerapan Tenaga Kerja di Kota Semarang. Jurnal Pembangunan Wilayah Dan Kota 14: 253-254. 